\title{
O Sistema de Tutoria no CLMD
}

\author{
Thaís Neuenfeld Philipsen - UFPEL - thaisclmd@gmail.com \\ Reginaldo Fabiano da Silva Afonso - UFPEL - regis.fab@ gmail.com \\ Gertrudes Aparecida Dandolini - UFPEL - ggtude@ gmail.com \\ João Artur de Souza - UFPEL - jartur@gmail.com \\ Inês Farias Ferreira - UFSM - inesfferreira10@ gmail.com
}

Resumo: Este artigo tem por objetivo descrever a experiência do primeiro ano de execução do curso de Licenciatura em Matemática a Distância (CLMD) da UFPel quanto ao funcionamento da tutoria. O CLMD oferece aos seus 120 alunos nas cidades pólos de Turuçu, Canguçu e Jaguarão um sistema de tutoria. A tutoria é realizada pelos tutores da sede e tutores do pólo através de diversos meios de comunicação. Além da função pedagógica, os tutores da sede são responsáveis por acompanhar o aluno em sua aprendizagem, motivando-o e orientando-o a seguir em frente e superar os desafios encontrados no decorrer do curso. Por outro lado, o tutor do pólo é o professor mais próximo do aluno, seu papel é de fundamental importância no decorrer do curso. Este deve, além de motivar o aluno, acompanhar de perto seu desempenho.

Palavras-Chave: Tutoria, Tecnologias, Ensino a distância, Matemática.

\section{The training system of CLMD}

\begin{abstract}
This article presents the experience of the first year of the training execution of the Distance Course of Degree in Mathematics (CLMD) of UFPel. CLMD offers to their 120 students in the Turuçu, Canguçu and Jaguarão cities a training system. The center tutors and tutors of the pole through several communications mean accomplish the training. Besides the pedagogic function, the tutors of the center are responsible for accompanying the student in his learning, motivating and guiding to proceed and overcome the challenges found in elapsing of the course. On the other hand, the tutor of the pole is the student's closest teacher; his role is fundamental in elapsing of the course. The tutor must motivate the student, to accompanying the students acting.
\end{abstract}

Keywords: Training, Technologies, Distance education, Mathematics

\section{Introdução}

A tutoria é parte indispensável para o sucesso de uma proposta de ensino a distância. Seu papel é facilitar o processo educativo do aluno. Um sistema de tutoria eficaz permite aproximar todos os sujeitos envolvidos na ação educativa, desde os professores pesquisadores até o aluno no pólo. Para tanto, o papel do tutor é imprescindível para a garantia dos canais necessários a fim de que haja comunicação entre todos os agentes envolvidos no curso.

No CLMD, o sistema de tutoria envolve o professor pesquisador, formador e tutores da sede e dos pólos. O professor pesquisador é o responsável pela produção do material

${ }^{1}$ Curso de Licenciatura em Matemática a Distância

V.4 № 2, Dezembro, 2006 
didático; o professor formador é responsável pela execução das aulas presenciais, acompanhamento da disciplina e orientação aos tutores; os tutores da sede são professores que realizam a tutoria a distância; e os tutores dos pólos são professores que buscam manter o aluno motivado e acompanhar de perto seu desempenho.

Tanto o pesquisador e formador quanto os tutores são parte de uma equipe multidisciplinar e, desta forma, devem estar abertos a discussões que vão além de sua área de formação específica, por isso, também devem ser capazes de contribuir para a construção do conhecimento coletivo. O desenvolvimento de inteligências coletivas deve ser motivado em um processo de trabalho multidisciplinar, especialmente na modalidade a distância.

Segundo Moran (2000), o papel principal do tutor é amparar os alunos em todos os momentos, sanando as dúvidas, orientando-os na resolução dos exercícios, estimulando a pesquisa e a leitura de livros e artigos. Também é sua função acompanhar o aluno durante toda a caminhada, de modo que ele não se sinta desamparado ou sozinho ao longo do processo de aprendizagem.

Na modalidade a distância, muito mais que na presencial, os papéis de cada sujeito envolvido no processo devem estar bem definidos. Assim, o aluno que escolhe hoje fazer um curso a distância terá que superar alguns desafios que aparecem no decorrer do caminho, como por exemplo, a ausência do professor diariamente em sala de aula, o estudo diário em grupo, a disciplina necessária na hora de estudar e a otimização do tempo, definindo prioridades de estudo e o período a ser dedicado a cada conteúdo e a cada disciplina. Além disso, o aluno necessita de alguém que o norteie durante o percurso, sendo este o papel do tutor.

A tutoria entra, então, como uma peça indispensável no processo de orientação dos alunos de um curso a distância (Peters, 2003, p.58). O tutor, aos poucos, deve mostrar para os alunos o quanto eles têm a ganhar no decorrer do trabalho, a partir das diferentes experiências que vão vivenciar ao longo do processo. Tutores e alunos, através dos recursos tecnológicos que hoje são disponibilizados, trabalham em prol de um mesmo resultado final: a construção do conhecimento e o desenvolvimento da personalidade e da racionalidade. Salientamos que dentro desses recursos que hoje são disponibilizados podemos dar suporte aos alunos em diversos locais ao mesmo tempo.

Pensando na necessidade de auxiliar os estudantes a vencer esses desafios e tantos outros que podem e vão acontecer durante o processo é que o curso de Licenciatura em Matemática a Distância da UFPEL vem utilizando diversas mídias para facilitar a execução da tutoria, visando a promover um melhor aprendizado.

Nos próximos tópicos explicaremos detalhadamente o sistema de tutoria e como estão sendo utilizadas essas tecnologias no atendimento ao corpo discente.

\section{O sistema de tutoria no CLMD}

O Sistema de Tutoria antevê o apoio sistemático às atividades pedagógicas de todos os participantes do CLMD e sua contínua capacitação. Para tanto, prevê:

- organização e planejamento da dinâmica de tutoria;

- planejamento da formação e treinamento dos tutores; 
- acompanhamento das práticas de ensino individuais a distância e da prática pedagógica orientada;

- planificação de atividades para recuperação da aprendizagem.

Portanto, um tutor deve possuir:

- capacidade de planejamento e de organização das atividades presenciais e a distância;

- capacidade de liderar e coordenar grupos de trabalho;

- facilidade de comunicação e relacionamento em grupo;

- conhecimento da proposta pedagógica do curso;

- conhecimento da utilização das tecnologias utilizadas no Curso;

- capacidade de orientação de trabalhos e de monografias;

- capacidade de elaborar relatórios;

- capacidade de identificar as dificuldades acadêmicas dos aprendizes em seu processo educativo;

- disposição para aperfeiçoar-se constantemente tanto do ponto de vista metodológico para o ensino a distância como na sua área de conhecimento.

Hoje, no CLMD, os tutores da sede (tutor a distância) têm como principais funções: auxiliar na elaboração de material didático, preparar as aulas, elaborar e resolver exercícios para disponibilizar no ambiente, elaborar provas e exames (em conjunto com o professor responsável), corrigir provas e exames, e atender os alunos a distância. Por sua vez, os tutores do pólo (tutor presencial) têm como principais atribuições: auxiliar os alunos na construção autônoma do conhecimento, motivá-los para o trabalho cooperativo, auxiliá-los a organizarem seus estudos, e manter os professores e tutores da sede informados sobre o que está acontecendo no pólo.

\section{Tecnologias utilizadas na tutoria a distância}

De acordo com os aspectos mencionados, o CLMD busca disponibilizar aos alunos do curso um suporte tutorial completo, através do qual se procura responder as dúvidas de forma rápida e completa, no prazo máximo de 24 horas, deixando o aluno confiante da sua aprendizagem. Além da certeza do apoio oferecido a distância, não se pode esquecer o auxílio que é oferecido pelo tutor que está no pólo para assessorar o aluno sempre que se faz necessário, dentro das suas necessidades.

Para que esse auxílio a distância possa, de fato, acontecer, são utilizados diversos recursos tecnológicos, síncronos e assíncronos. Dentre os principais podemos citar o Moodle, o msn e o skype, além do e-mail e do telefone. A seguir, falamos sobre cada um deles, abordando algumas de suas características principais e salientando os mais utilizados atualmente no curso.

O Moodle é o ambiente de aprendizagem utilizado pelo CLMD. O curso desenvolve-se em torno deste ambiente. Na página inicial, encontram-se, entre outras informações, o cronograma das atividades presenciais, as datas de provas, normas do curso, e o item "participantes", onde podemos acessar a identificação de cada aluno ou professor, sendo possível deixar-lhes mensagens. Também encontramos os fóruns gerais, um recurso assíncrono. Nele, além disso, são disponibilizadas as disciplinas do curso, sendo que dentro de cada uma delas encontram-se o plano de ensino detalhado, o material relativo aos conteúdos, listas de exercícios, tarefas, sugestões de leituras complementares, fóruns 
da disciplina, etc. Existem dois tipos de fóruns: os gerais, que abordam o curso como um todo, incluindo dúvidas sobre informática, notícias e avisos, e também existem os fóruns de cada uma das disciplinas. Nestes últimos, por exemplo, o aluno posta uma dúvida na espera de uma resposta que possa auxiliá-lo na resolução de terminada atividade. Tanto os alunos como os professores podem responder, de forma que o auxílio é mútuo e muito eficaz, pois de acordo com Azevedo (2006),

"Mais do que o sujeito "autônomo", "autodidata", a sociedade hoje requer um sujeito que saiba contribuir para o aprendizado do grupo de pessoas do qual ele faz parte, quer ensinando, quer mobilizando, respondendo ou perguntando. É a inteligência coletiva do grupo que se deseja pôr em funcionamento, a combinação de competências distribuídas entre seus integrantes, mais do que a genialidade de um só”.

Na Figura 1 podemos ver a tela inicial do ambiente de aprendizagem Moodle do CLMD.

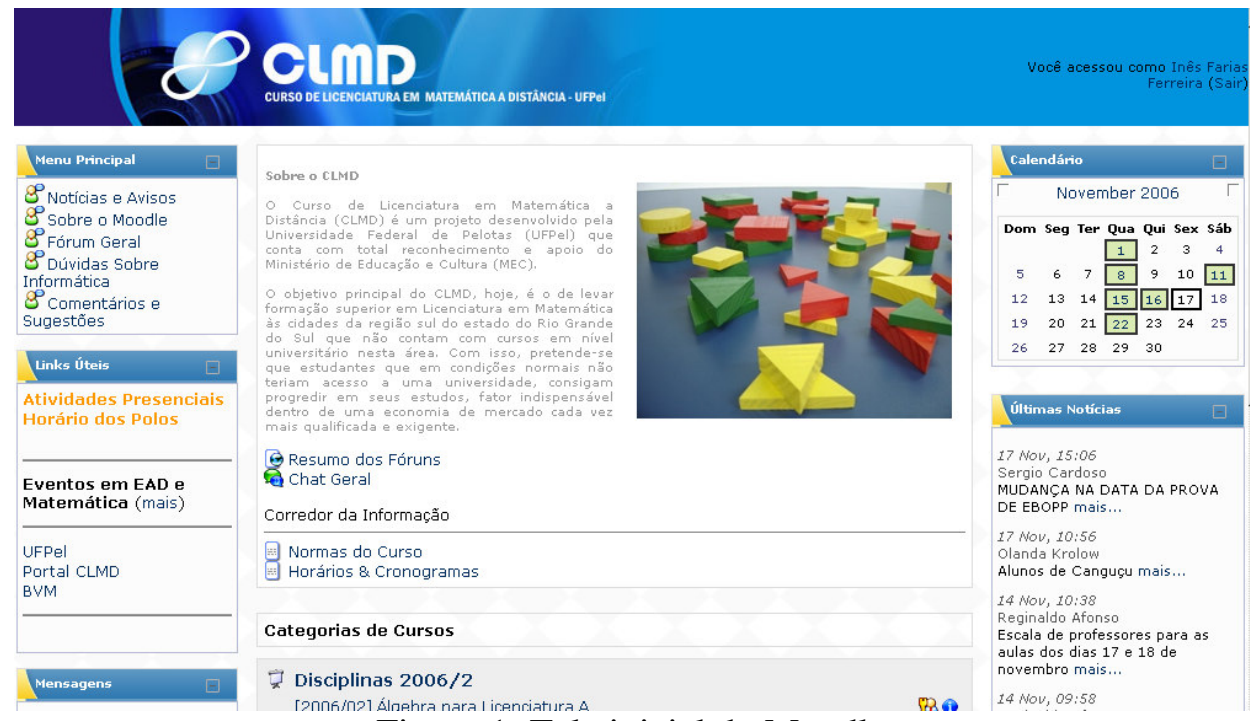

Figura 1: Tela inicial do Moodle

Outro recurso utilizado dentro do Moodle é o chat. Podemos marcar uma determinada data e hora com os alunos e fazer um bate-papo síncrono, discutir questões e sanar dúvidas de conteúdos. Todo o chat fica registrado dentro do ambiente e é disponibilizado para acessos posteriores. Os alunos também possuem um espaço destinado para recados, onde enviam uma mensagem específica para um colega ou para o professor.

Cabe salientar, também, que o Moodle suporta a linguagem Latex, que possibilita a inserção de fórmulas matemáticas. Essa linguagem está sendo incorporada aos poucos nas explicações, facilitando o entendimento dos alunos, pois os mesmos ainda não dominam completamente esta ferramenta.

O Moodle é visto como a porta da universidade para o aluno de um curso a distância, pois neste ambiente ele encontra as informações necessárias sobre seu curso e sobre as disciplinas em geral, o material didático de base para o aprendizado, as indicações para complementar seus estudos, as tarefas a serem realizadas, exercícios de orientação para 
assimilar melhor os conteúdos abordados, enfim, o suporte necessário para a longa jornada acadêmica.

O msn é o recurso mais utilizado para conversas síncronas entre alunos e tutores, estando os alunos em casa ou no pólo. O msn é um programa gratuito que pode ser baixado da internet.

Para facilitar o trabalho de tutoria, é feita uma escala semanal, em que sempre há pelo menos um tutor disponível para assessorar os alunos nos três turnos, de segunda a sexta. O sábado é o dia destinado para os encontros presencias nos pólos. Aqui se percebe que, em acordo com o que é dito por Moran (2006), nesta modalidade de ensino tem-se uma maior flexibilidade em todos os sentidos, onde uma parte de cada disciplina será predominantemente presencial e outra predominantemente virtual, sendo o mais importante neste processo o aprender e não a imposição de um padrão único de ensinar.

Podemos, também, através do msn, mandar e receber arquivos, falar sincronamente e utilizar a webcam. Se quisermos, podemos salvar as conversas para disponibilizá-la posteriormente. Por exemplo, no caso de uma explicação de conteúdo ou resolução de exercício. Salientamos que, para podermos falar com alguém através desse programa, precisamos adicionar essa pessoa a nossa lista de contatos. A partir desse programa vemos a interação que acontece entre os alunos dos três pólos (Canguçu, Jaguarão e Turuçu) onde o curso está em andamento.

O skype, por sua vez, é um programa que realiza ligações telefônicas, vídeo-conferência e bate-papo através da internet, de forma síncrona. Assim como o msn, também é um programa que encontramos disponível na internet de forma gratuita. No CLMD, ainda é menos utilizado por ser pouco conhecido entre os alunos, mas tem uma boa aceitação entre os que já são usuários. Como no $m s n$, para podermos conversar utilizando o skype é necessário adicionar esta pessoa a nossa lista de contatos. Os alunos que já descobriram como é simples a comunicação através desse programa usam o msn apenas para "conversas" rápidas.

Com relação ao e-mail, sabe-se que é muito conhecido e largamente utilizado entre os usuários de informática de modo geral. Cada aluno deve ter o seu próprio correio eletrônico, que é feito pela internet de forma gratuita. Para isso, existem diversos provedores, dentre os quais podemos citar Terra, Pop, Gmail, Yahoo e Bol. Este é um tipo de recurso assíncrono, utilizado para mandar recados ou arquivos. Dentro do próprio ambiente podemos organizar uma lista com os endereços dos demais colegas e professores.

O telefone, por fim, é um meio de comunicação utilizado quando os recursos da informática estão indisponíveis no momento, ou para recados breves. É pouco utilizado no curso entre professores e alunos, no entanto, é mais utilizado entre o tutor do pólo e os alunos.

Através dos recursos acima citados, portanto, podemos esclarecer dúvidas, orientar no trabalho de pesquisa, oferecer um foco a ser seguido no estudo e estar constantemente estimulando o aluno a seguir em frente, a acreditar no seu potencial e buscar superar os desafios para alcançar os objetivos almejados. 
Cabe salientar que o papel do tutor do pólo é de extrema importância no sistema de tutoria, já que é ele a pessoa que tem contato direto com o aluno. É através dele que o aluno sente que existem pessoas caminhando ao seu lado, o que é fundamental, pois alguns, pelo menos em um primeiro momento, não conseguem se sentir à vontade no uso das tecnologias descritas acima. O tutor do pólo, nesses casos, funciona como mediador entre o aluno e o tutor da sede.

\section{Conclusões}

De acordo com o exposto acima, a tutoria tem sido bem aceita pelos alunos, tanto a da sede como a do pólo. A certeza da boa aceitação e dos bons resultados reside no fato de que a procura por auxílio tem crescido de forma considerável, especialmente no turno da noite.

Muitas vezes, o aluno sai do trabalho e vai direto para o pólo para estudar, concluir tarefas e trabalhos, pesquisar, resolver exercícios, enfim, buscar pelo crescimento pessoal e, assim que chega, encontra uma equipe pronta para ajudá-lo no que for preciso.

Não foi somente uma ou duas, mas inúmeras as vezes em que atendemos diversos alunos ao mesmo tempo, especialmente em semana de prova, onde o aumento da procura é natural. Também notamos que os próprios alunos estudam juntos e procuram aprender em grupo. Um aluno busca pelo auxílio via $m s n$, por exemplo, e assim que sanou sua dúvida, retorna para o estudo em grupo e explica para os colegas. Eles mesmos relatam fatos desse tipo que aconteceram e com certeza, seguirão acontecendo, pois o objetivo de aprender é comum e eles, enquanto alunos, já entenderam que ajuda mútua é o melhor caminho a ser seguido.

Para ilustrar esta interação entre tutor e aluno, através da Figura 2 mostramos uma conversa entre uma aluna e o tutor da sede, onde questões referentes a disciplina de Geometria Espacial é abordada.

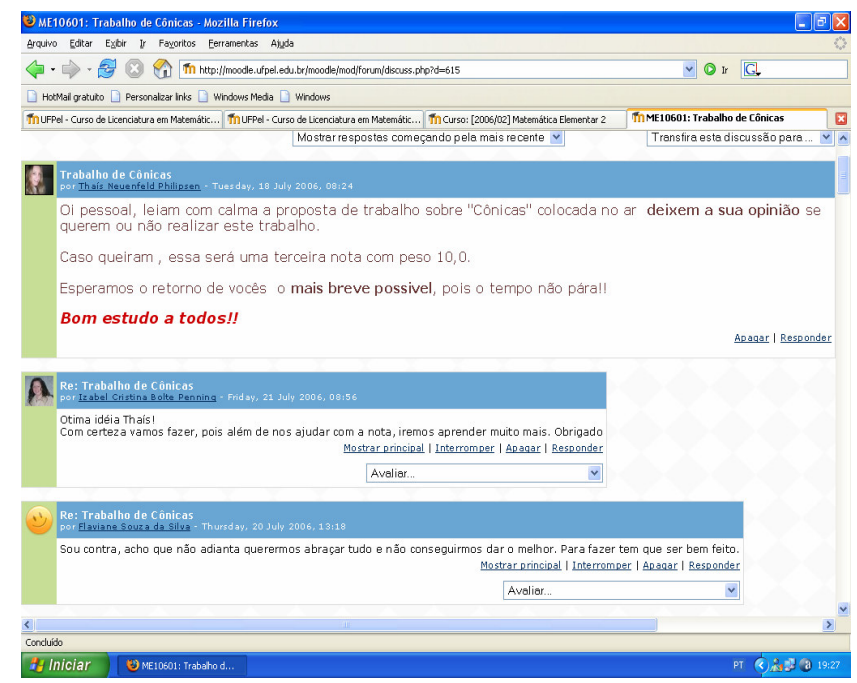

Figura 2: Diálogo entre professora formadora e aluna

Observe-se que, inicialmente, a linguagem pode não ser compreendida, mas conforme os símbolos começam a se tornar comuns, a comunicação acontece de forma simples e 
natural. A necessidade de adaptação da linguagem faz parte desse processo de construção de conceitos, de desenvolvimento das idéias, de troca de experiências. Quanto mais o aluno busca por ajuda, mais simples será a sua comunicação, tanto com os professores como com os próprios colegas.

Os bons resultados entre os alunos, tanto na forma pedagógica como pessoal, comprovam que o sistema de tutoria tem dado resultados positivos em todos os aspectos. Esse sistema, da forma como foi exposto, tem sido um suporte firme para o aluno caminhar. A segurança de ter profissionais ao seu lado, trabalhando de forma séria e comprometida, estimula o desenvolvimento contínuo, a superação de desafios e a certeza da aprendizagem no decorrer da jornada. $O$ aluno sente-se confiante e com forças para seguir em frente, para buscar mais, para alcançar seus objetivos.

O aperfeiçoamento na forma do sistema de auxílio através da tutoria on-line é contínuo e está intimamente ligado às tecnologias que estão sendo oferecidas no mercado. Temos a certeza de que o suporte necessário está sendo desenvolvido e, pouco a pouco, vem sendo aprimorado para melhor atender o aluno, de forma rápida e simples, de acordo com a capacidade de compreensão de cada estudante.

\section{Referências bibliográficas}

AZEVEDO, WILSON. EAD - Novo professor e novo aluno. Disponível em $<$ http://www.escolanet.com.br/sala_leitura/novprof_novaluno.html >. Acesso em $23 \mathrm{de}$ setembro de 2006.

MORAN, JOSÉ MANUEL. Ensino e aprendizagem inovadores com tecnologias. Disponível em <http://www.eca.usp.br/prof/moran/inov.htm $>$. Acesso em 02 de outubro de 2006.

MORAN, JOSÉ MANUEL. Mudar as formas de ensinar e aprender com tecnologias. Disponível em: <http://www.eca.usp.br/prof/moran/textost.htm> Acesso em 10 de junho de 2006.

PETERS, OTTO, Didática do ensino a distância. São Leopoldo: Editora Unisinos. 2003. p. 58-60. 